\title{
Synthesis and Optical Properties of Soluble Isoxazole-Containing Poly( $p$-phenylene)-Related Polymer
}

\author{
Kensuke NaKa, ${ }^{\dagger}$ Etsuo HoriI, and Yoshiki CHUJO ${ }^{\dagger}$ \\ Department of Polymer Chemistry, Graduate School of Engineering, Kyoto University, \\ Yoshida, Sakyo-ku, Kyoto 606-8501, Japan \\ (Received April 22, 1999)
}

KEY WORDS Isoxazole / Palladium-Catalyzed Cross-Coupling Reaction / Poly( $p$-phenylene) /

Polymeric light-emitting diodes (LEDs) have recently attracted attention. ${ }^{1}$ These polymers composed of highly $\pi$-deficient heterocycles such as pyridine and oxadiazole ring are typically $n$-dopable with high electron affinity showing greater tendency for transporting electrons. ${ }^{2,3}$ Although isoxazole derivatives are $\pi$-deficient heterocycles, polymeric materials having isoxazole ring have been paid less attention. Several poly(isoxazole)s have been prepared by 1,3-dipolar polycondensations of dinitrile $N$-oxide compounds with diynes ${ }^{4}$ and by reaction of poly(diethylbenzene) with hydroxylamine. ${ }^{5}$ However, examples of soluble polymers having isoxazole unit in the main chain are limited. Preparation of soluble polymers by 1,3-dipolar polycondensation was reported by Kanbara et al. ${ }^{6}$ This note describes the synthesis and optical properties of a soluble isoxazole-containing poly ( $p$-phenylene)-related polymer by palladium-catalyzed cross-coupling reaction of an isoxazole monomer with dioctylbenzene-1,4-bisboronic acid.

\section{EXPERIMENTAL}

\section{Measurements}

${ }^{1} \mathrm{H}$ NMR and ${ }^{13} \mathrm{C}$ NMR spectra were obtained with a JEOL JNM-EX270 spectrometer $\left(270 \mathrm{MHz}\right.$ for ${ }^{1} \mathrm{H}$ NMR and $67.9 \mathrm{MHz}$ for ${ }^{13} \mathrm{C} \mathrm{NMR}$ ). TGA was performed on a Shimadzu DT-30 instrument $\left(10^{\circ} \mathrm{C} \mathrm{min}{ }^{-1}\right)$. UV spectrum was recorded on a JASCO V-530 spectrophotometer. Fluorescence spectrum was obtained on a Perkin Elmer LS50B luminescence spectrometer. Gel permeation chromatographic analysis was carried out on a Tosoh $\mathrm{G} 4000 \mathrm{H}_{\mathrm{XL}}$ column using tetrahydrofuran (THF) as an eluent with calibration using standard polystyrene samples. DSC analysis was carried out on a Seiko DSC200 instrument using $6 \mathrm{mg}$ exactly weighed sample.

\section{Materials}

Unless stated otherwise, all reagents and chemicals were obtained from commercial sources and used without further purification. Toluene was distilled under nitrogen over $\mathrm{CaH}_{2}$. 3,5-Bis(4-bromophenyl)isoxazole (1) was synthesized from 4'-bromo-2-(4-bromobenzoyl)acetophenone according to a literature. ${ }^{7}$ Dioctylbenzene-1,4bisboronic acid (2) was prepared as reported. ${ }^{8}$

\section{Polymerization}

To a solution of $1(77.8 \mathrm{mg}, 0.205 \mathrm{mmol}), 2(80.0 \mathrm{mg}$, $0.205 \mathrm{mmol})$, and $\mathrm{Pd}\left(\mathrm{PPh}_{3}\right)_{4}\left(2.0 \mathrm{mg}, 3.7 \times 10^{-6} \mathrm{~mol}\right)$ in toluene $(3.0 \mathrm{ml})$ were added $1.5 \mathrm{ml}$ of $2 \mathrm{M} \mathrm{Na}_{2} \mathrm{CO}_{3}$ under nitrogen. The mixture was stirred for 2 days under reflux. The product mixture was poured into $100 \mathrm{ml}$ methanolwater $(4: 1, \mathrm{v} / \mathrm{v})$ and the precipitate was filtrated. To separate traces of inorganic salts, the polymer was extracted with toluene in a Soxhlet apparatus for $12 \mathrm{~h}$. The resulting solution was evaporated in vacuo to give $94.8 \mathrm{mg}(0.182 \mathrm{mmol}$, yield $89 \%)$ of the polymer $(3) .{ }^{1} \mathrm{H}$ $\operatorname{NMR}\left(\mathrm{CDCl}_{3}\right): \delta 0.85\left(\mathrm{CH}_{3}, \mathrm{t}, 6 \mathrm{H}\right), 1.20\left(\mathrm{CH}_{2}, \mathrm{br}, 24 \mathrm{H}\right)$, $2.63\left(\mathrm{Ph}-\mathrm{CH}_{2}, \mathrm{br}, 4 \mathrm{H}\right), 6.96$ (isoxazole, s, $1 \mathrm{H}$ ), 7.20 (Octyl- $\mathrm{C}_{6} \mathrm{H}_{2}$-Octyl, s, 2H), $7.54\left(\mathrm{C}_{6} \mathrm{H}_{4}, \mathrm{~m}, 4 \mathrm{H}\right), 7.97$ $\left(\mathrm{C}_{6} \mathrm{H}_{4}, \mathrm{~m}, 4 \mathrm{H}\right) .{ }^{13} \mathrm{C}$ NMR $\left(\mathrm{CDCl}_{3}\right) \delta 14.41,23.11,29.62$, 29.99, 31.39, 32.30, 33.14, 97.88, 126.09, 127.04, 128.12, $130.48,131.36,132.67,138.13,140.83,144.26,163.32$, 170.85. Anal. Calcd for $\mathrm{C}_{37} \mathrm{H}_{45} \mathrm{NO}$ : $\mathrm{H} 8.73$; C 85.5; N 2.69; O 3.08. Found: H 8.71; C 83.25; N 2.47; O 3.19.

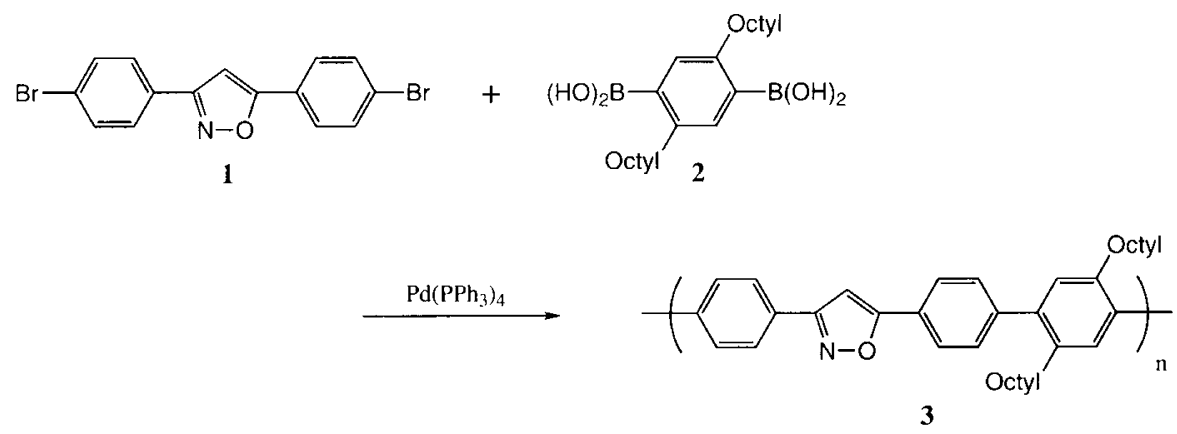

Scheme 1.

\footnotetext{
$\dagger$ To whom correspondence should be addressed.
} 


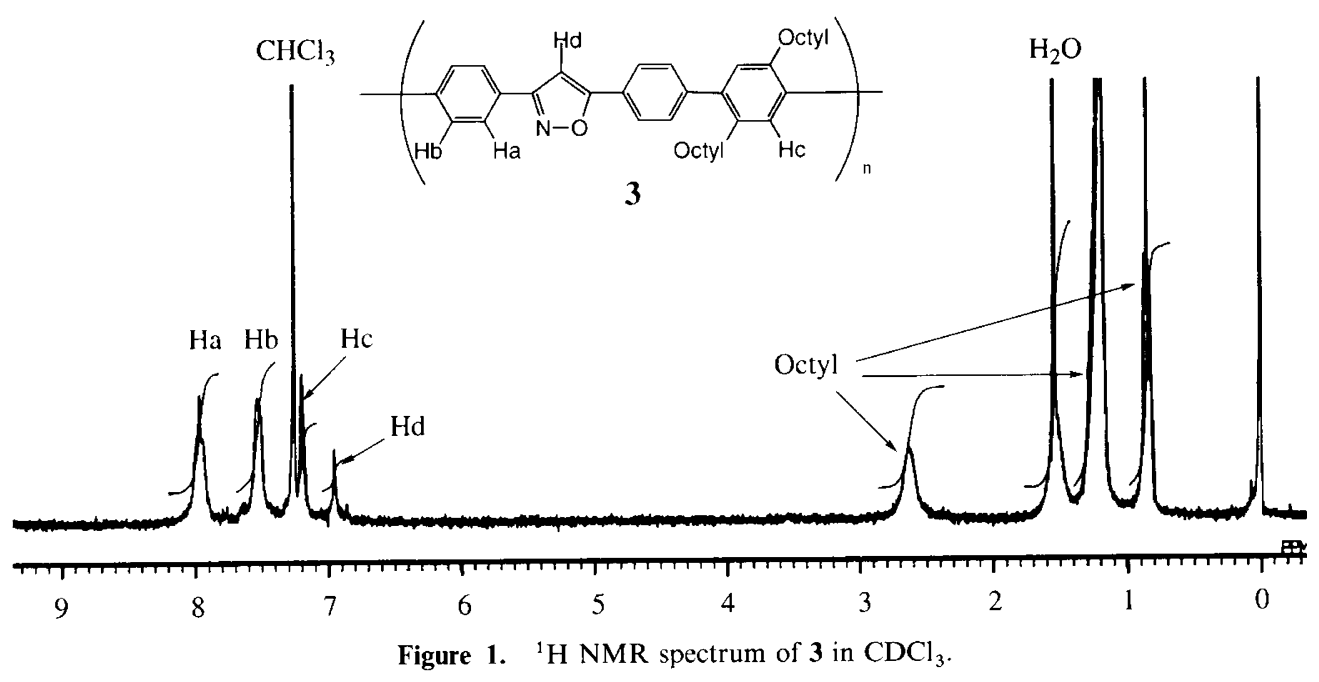

\section{RESULTS AND DISCUSSION}

Polymerization was carried out by palladium-catalyzed cross-coupling reaction of the isoxazole monomer (1) with dioctylbenzene-1,4-bisboronic acid (2). Equimolar amounts of 1 and 2 were treated with $2 \mathrm{~mol} \% \mathrm{Pd}\left(\mathrm{PPh}_{3}\right)_{4}$ in a heterogeneous system of water $\left(\mathrm{Na}_{2} \mathrm{CO}_{3}\right)$ /toluene under reflux condition. The mixture was poured into a large quantity of methanol-water $(4: 1, \mathrm{v} / \mathrm{v})$. After the precipitate was extracted with toluene in a Soxhlet apparatus, polymer (3) was obtained in $89 \%$ yield. The polymer was soluble in common organic solvents such as $\mathrm{CHCl}_{3}$ and THF. The polymer was dissolved in THF and subjected to GPC measurement. The numberaverage molecular weight $\left(M_{n}\right)$ and molecular weight distribution (MWD) of the polymer were $M_{n}=74000$ and $\mathrm{MWD}=3.37$, respectively.

Reduction of the amount of the catalyst decresed the yield and molecular weight of the polymer. Polymerization of equimolar amounts of 1 and 2 with $1 \mathrm{~mol} \%$ of $\mathrm{Pd}\left(\mathrm{PPh}_{3}\right)_{4}$ in a water $\left(\mathrm{Na}_{2} \mathrm{CO}_{3}\right) /$ toluene under reflux condition for 2 days gave the polymer in $48 \%$ yeild. The number-average molecular weight of the polymer was 7000 .

Elemental analysis data of the polymer were in agreement with calculated values for the ideal structure. The structure of the polymer was supported by ${ }^{1} \mathrm{H}$ and ${ }^{13} \mathrm{C}$ NMR. Figure 1 shows the ${ }^{1} \mathrm{H}$ NMR spectrum of the polymer. The peak attributable to $4-\mathrm{H}$ proton of the isoxazole ring was observed at $6.9 \mathrm{ppm}$. Peak areas agreed with structure. The ${ }^{13} \mathrm{C}$ NMR spectrum of the polymer shows three peaks at $163.32,170.85,97.88 \mathrm{ppm}$ due to the carbons of isoxazole ring.

Thermogravimetric analysis (TGA) for 3 showed relatively high thermal stability with $5 \%$ weight loss of the polymer at $352^{\circ} \mathrm{C}$ under nitrogen. The differential scanning calorimetry (DSC) thermogram of the polymer showsed no melting point below $200^{\circ} \mathrm{C}$.

The UV-Vis absorption spectrum of the polymer showed a peak due to the $\pi-\pi^{*}$ transition at $380 \mathrm{~nm}$. Under ultraviolet light irradiation, the polymer was strongly fluorescent with purple emission. Figure 3 displays a fluorescence emission spectrum of the polymer recorded in chloroform with excitation wavelength of

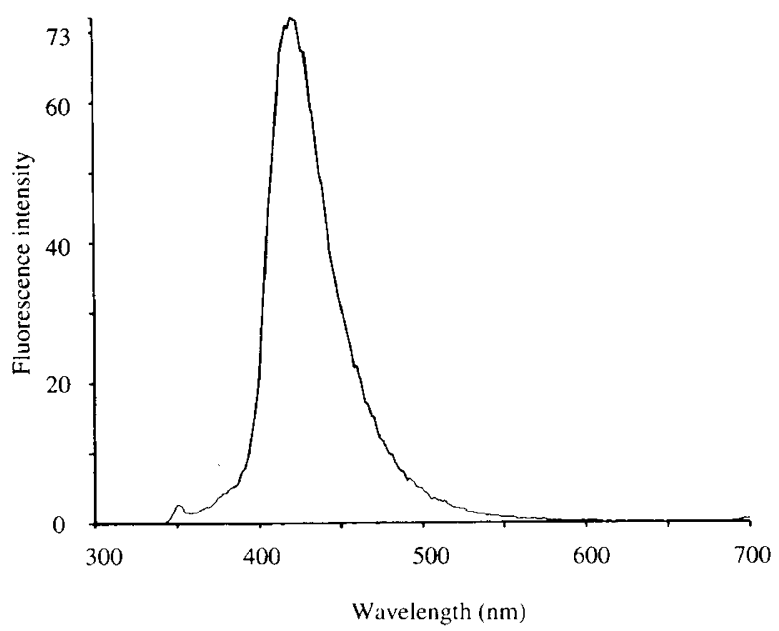

Figure 2. Fluorescence emission spectrum of $\mathbf{3}$ in chloroform at room temperature (excitation wavelength at $350 \mathrm{~nm}$ ).

$350 \mathrm{~nm}$. The fluorescence spectrum exhibited the emission maximum at $423 \mathrm{~nm}$. Although poly(arylene)s containing isoxazole units as well as optical active carbazole units show strong fluorescence with peaks at $340-490 \mathrm{~nm},{ }^{6}$ our results indicate for the first time of a fluorescent soluble isoxazole-containing poly ( $p$-phenylene)-related polymer. Electron transfer from $p$-phenylene unit to $\pi$-deficient isoxazole unit may thus occur in excited states of the polymer.

\section{REFERENCES}

1. M. Strukelj, F. Papadimitrakopoulos, T. M. Miller, and L. J, Rothberg, Science, 267, 1969 (1995).

2. Q. Pei and Y. Yang, Chem. Mater., 7, I568 (1995).

3. A. J. Epstein, J. W. Blarchford, Y. Z. Wang, S. W. Jessen, D. D. Gebler, L. B. Lin, T. L. Gustafson, H.-L. Wang, Y. W. Park, T. M. Swager, and A. G. MacDiarmid, Synth. Met., 78, 253 (1996).

4. Y. Iwakura, K. Uno, S-J. Hong, and T. Hongu, Polym. J., 2, 36 (1971).

5. W. Bracke, J. Polym. Sci, Part A-l, 10, 983 (1972).

6. T. Kanbara, T. Ishii, K. Hasegawa, and T. Yamamoto, Polym. Bull., 36, 673 (1996).

7. O. Dann, H. Fick, B. Pietzner, E. Walkenhorst, R. Fernbach, and D. Zeh, Liebigs Ann. Chem., 160 (1975).

8. M. Rehahn, A. D. Schlüter, and G. Wegner, Makromol. Chem. 191, 1991 (1996). 